\title{
Geomodels of space monitoring of water bodies
}

\author{
Vasyl Trysnyuk ${ }^{1}$, Taras Trysnyuk ${ }^{1}$, Anatolii Nikitin ${ }^{1}$, Anatolii Kurylo ${ }^{1}$, and Olga Demydenko ${ }^{1}$ \\ ${ }^{1}$ Institute of telecommunications and global information space of NAS of Ukraine, Kyiv, Ukraine
}

\begin{abstract}
Theme of the paper is the solution of flooding geomodels creation for Dniester river basin territory, which uses contact and remote measurements. Natural and anthropogenic factors causing groundwater level rising were analyzed for localization of flooded zones and forecasting of geometric characteristics. Geographic information systems for researched area include the spatial binding of the hydrological elements and observation points, digital model of relief preparation, basin allocation catchment, flooded areas modeling. Structural features include the size and shape of object, brightness disposal within the object, image texture, some others. Possibility of available remote sensing data use allows reducing temporal and economic cost for conducting additional ground measurements for possible flooded areas determining. These methods of geomodels creation are realized for the territory of Dniester Canyon, the hydrogeologic feature of which is connected to the Upper Cretaceous horizon and groundwater.
\end{abstract}

\section{Introduction}

This research objective is to create cartographic models of potential flooded zones in the Dniester river basin in Ukraine. Environmental researches, particularly in the context of anthropogenic influence, show negative dynamics of flood events statistical frequency. In order to make well-timed decisions of possible negative consequences preventing or eliminating, remote sensing methods are being actively used. Development of new and improving the existing geomodels creating methods, just as potential flood zones definition, is possible on the basis of remote and contact measurements comprehensive using. It also requires considering hydrogeological conditions diversity and geographical conditions of the researched area [1-3].

Every year the problem of new and new territories groundwater flood is growing. It leads to sanitary and epidemiological deterioration, to groundwater and soil chemical composition changing, to corrosion activity increasing which relate to engineering structures foundation, to dangerous geological events activation, etc.

Experimental researches of anthropogenic factors that were associated with flood in the Dniester river basin are based on expert assessment and information technology methods. Geomorphological researches, geological researches of Dniester canyon, Dniester terrace formation history was made by O. Adamenko, A. Bohutskiy, A. Yatshishin, S. Rudnitskiy, E. Romer. Current environmental situation researchers in the territory of Dniester anti-flood area are considered by Y. Adamenko, D. Zorin, Y. Semchuk and some other scientists. Scientometric analysis results showed a number of environmental problems in this area which need to solve.

\section{Results}

The aim of the research is to solve a scientific and practical task of potential flood geomodels creation substantiation in Dniester river basin, which has to base on aerospace and ground measurements.

Prevention of emergencies associated with flood in Dniester river basin requires continuous monitoring with analysis and assessment of received data. Flooded areas detection is carried out using remote and contact methods.

The ecological danger of flooding occurs in such landscapes as river valleys terraced bottoms. It takes the form of destructive coastal erosion, while high water disasters take place in foothills within the boundaries of floodplains. Among geomorphological processes, most hazardous for the environment, are landslides. This phenomenon is wide-spread in areas of erosion-shifting interfluve and hilly lowlands, landslides and shoals - in mid-high mountains with stiff slopes [4-7].

Chemical pollution of the territory does not have a strong coherence with landscape type; it tends to local sources of influence, around which anthropogenic geochemical anomalies are formed. Totally, there are nearly 18 man-made anomalies in the Dniester Canyon which occupy southern boundary of Ternopil region.

Contact methods allow accurate measurements of the groundwater depth, but some errors can occur in the process their boundaries establishment [8-13]. These methods also require large quantity of material and labor resources.

In the process of degree of risk for the geomodels hierarchical structure formation determining, interval estimates method using helps to make operational decisions 
to prevent consequences of dangerous engineeringgeological processes in uncertain conditions. This method requires establishing dependencies between model parameters that characterize various possible situations of researched areas, using expert assessment and statistical analysis.

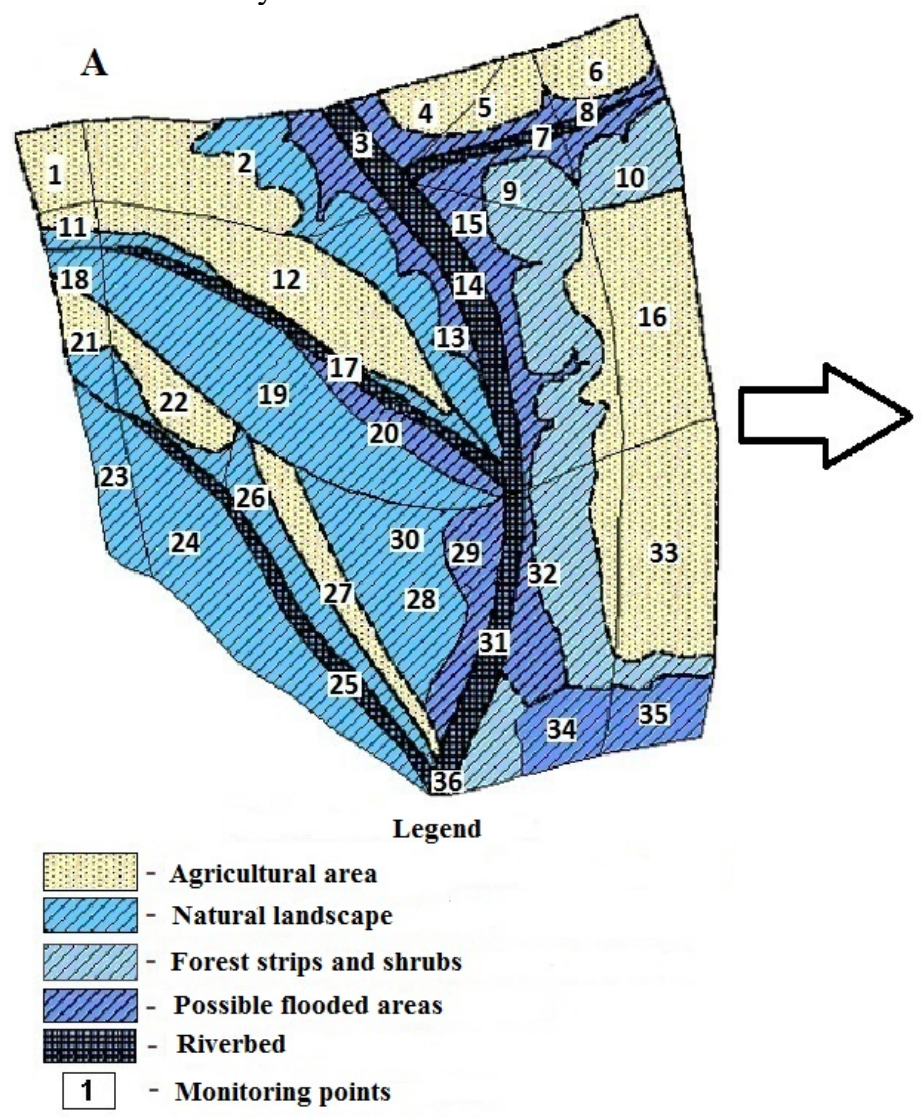

This way contributes to increase the accuracy of flooded zones localization with different degrees of danger $[17,18]$.

Geographic information systems for researched area include the spatial binding of the hydrological elements and observation points, digital model of relief preparation, basin allocation catchment, flooded areas modelling (Fig. 1).

Fig. 1. Cartographic and graph model of the flood on Dniester river segment in rainy weather: A) Map of flooded territory; B) Graph representation of the model.

Proposed flood mapping representation and graph model representation of the Dniester region are basing on aerospace and ground survey using, which include data analysis for obtaining topographical or special maps and digital relief model construction.

Constructed graph shows the points of research and catchment area branching peculiarities on the territory. The final aim of proposed methodology is to assess and to consider actions of flood and deformation accidents struggling [14-16].

Natural and anthropogenic factors leading to groundwater level rise were adjusted for flooded zones localization and geometric characteristics dynamics forecasting. Possible unfavorable processes in flooded zones were established factored in the characteristics of the territory. Four flood categories depending on groundwater lever occurrence, causing factors and possible consequences were separated. Categories I and II accords to areas with groundwater depth is less than $2.5 \mathrm{~m}$, where dangerous phenomena occur. Category III accords to possible flooded areas with a groundwater depth from 2.5 to $4 \mathrm{~m}$, where tendency to groundwater level rise can be noticed. Areas in category IV cannot be flooded, because there are no predictions for flooding if groundwater level is deeper than $4 \mathrm{~m}$.
Cosmobioindication method (by G. Krasovskiy) enables to make monitoring of waterlogged lands. This method [19-21] is based on vegetation conditions (determined by vegetation indexes measurement) depending on land waterlog degree. The application of this method is limited to unpowered soybean soils.

It is necessary to assess possible risk of groundwater shallow occurrence to determine degree of danger for researched territory. Creation of new and improving existing methods of geomodel developing for potential flooded areas is possible only after comprehensive remote sensing results and ground measurements using. Also requirement is to take hydrogeologic conditions diversity and geographical specific of the area into account.

Fig. 2 shows the structural scheme to develop geomodel for probable flooded zones according to danger degree.

There are four stages to make cartographic model with different flooding probabilities. At the first stage, it is necessary to create cartographic models of probable flooded areas based on the rules of fuzzy production system. Also SRTM (radar topographic survey) data and available ground measurements data have to be used. $[22,23]$.

At the next stage, thematic decoding of aerospace images is made in order to identify geomorphologic 
elements and potential sources of anthropogenic impact for developing of cartographical models of natural and man-made flood based on only classification characteristics assessment scale. If it is necessary, photogrammetric image processing is executed. Third stage is to specify the flooding geomodel through overlay operations on cartographic models built on the base fuzzy production system rules and interval scale of evaluation. At the final stage, a complex hierarchical geomodel of probable flooding zones (based on danger degree) is created. It is made through specified geomodel and anthropogenic flood overlaying.

Let us consider the features used in visual analysis of remote survey materials or formalized in the methods of space images computer analysis. Decryption features can be divided into two main groups - brightness and structural. During visual analysis of images bright features group includes image photon (for monochromatic images), such color characteristics as color tone, color saturation and "lightness" (for color, spectrozonal and synthesized images). During decoding of digital images rendered on the display screen, brightness equivalents of image (for panchromatic), zonal brightness equivalents (for multizonal survey) and equivalent of effective scattering area (for radar images) are the brightness features. If synthesis procedure is being used in conditional colors for multizonal images visualization, then the color characteristics are also being analyzed.

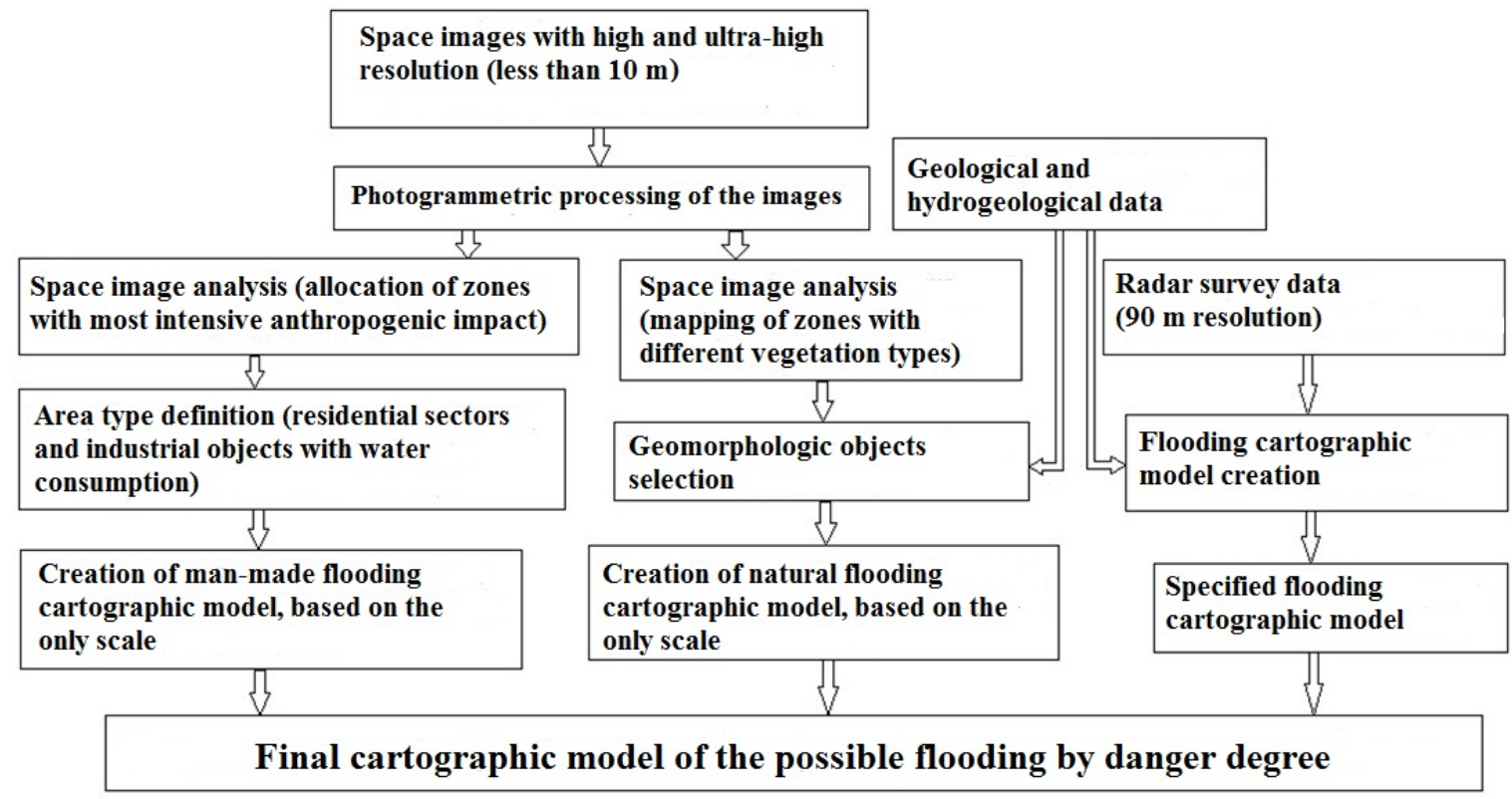

Fig. 2. Method of creating flood cartographic model by danger degree.

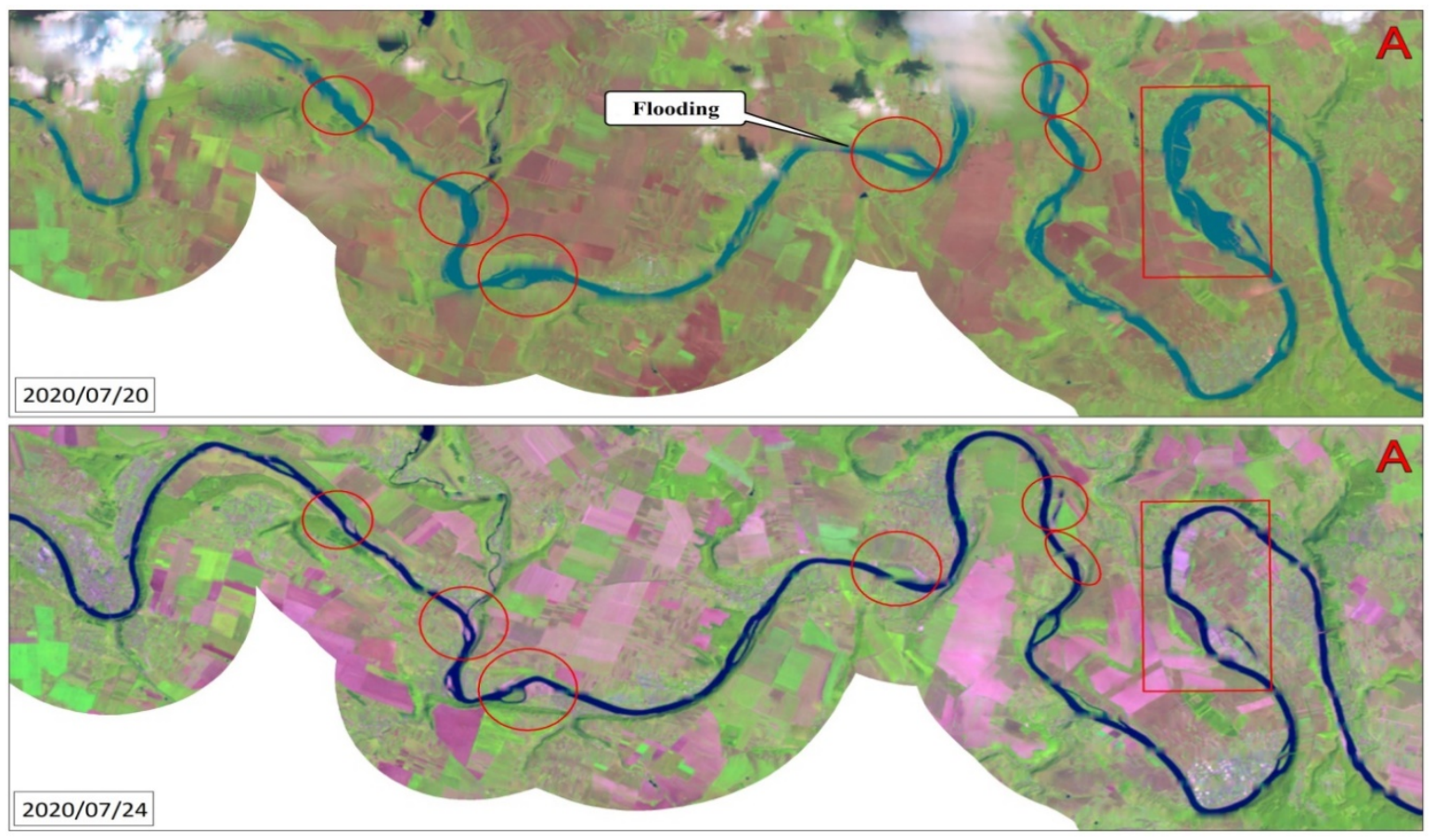

Fig. 3. Flooded areas in Dniester river basin between Dobrilyany and Ustia villages in 2020 is on a fragment of space image SENTINEL 2 (10 m resolution). 
Structural features include the size and shape of object, brightness disposal within the object, image texture, some others [24-35]. The initial source for the space images thematic analysis is various thematic maps. Together they give information about localization of objects and spatial disposal of indicators. This disposal characterizes ecological situation in the environment or anthropogenic impact level in its components, localization of impact sources and its scale. Therefore, main processes in space images thematic analysis are represented as images segmentation for planar and linearly extended objects identifying, as Fig. 3 shows.

Remote sensing methods allow to make flood monitoring and to analyze its dynamics, but they have a number of disadvantages due to high difficulty of data analysis and delay in obtaining the space images.

Flooded zones localization on space images is carried out on indirect features, such as presence of floodplains, swamps and relief depressions. Flooded areas mapping is possible on threshold values of mathematical expectation and dispersion of color intensity on red, green and blue channels [36-49].

Digital panchromatic image with a $10 \mathrm{~m}$-resolution (4800 x 4800 pixels) was analyzed in ERDAS IMAGINE software using controlled classification method.

\section{Conclusions}

Methods for geomodels making for probable flooded zones were developed and implement for territories in Dniester river basin. Its geomodels consider degrees of danger which formed in conditions of insufficient information.

Scientometric analysis of geomodels creating methods for flooded territories showed that possible flooded areas timely detection and prediction of dangerous accidents is possible only with complex use of remote and ground measurements with their subsequent rationing and analyze.

Possibility of available remote sensing data use allows reducing temporal and economic cost for conducting additional ground measurements for possible flooded areas determining. While the accuracy of predictive parameters do not reducing.

The developed cartographic models of possible flooding areas allow determining and visually assessing the degree of flooding under different modes of pressure horizons use, which have a hydraulic connection with groundwater. These methods of geomodels creation are realized for the territory of Dniester Canyon, the hydrogeologic feature of which is connected to the Upper Cretaceous horizon and groundwater.

\section{References}

1. O. Trofymchuk, Y. Yakovliev, V. Klymenko, Y. Anpilova, Geomodeling and monitoring of pollution of waters and soils by the earth remote sensing. International Multidisciplinary
Scientific GeoConference - SGEM, 19, 1.4 (2019)

2. O.M. Trofymchuk, Yu.I. Kaliukh, V.A. Dunin, Y.A. Berchun. On the Possibility of Multi-Wavelength Identification of Defects in Piles. Cybernetics and Systems Analysis, 54 (2018)

3. I. Kaliukh, V. Senatorov, N. Marienkov, O. Trofymchuk, K. Silchenko, T. Kalyukh, Arrangement of deep foundation pit in restricted conditions of city build-up in landslide territory with considering of seismic loads of 8 points. Geotechnical Engineering for Infrastructure and Development - Proceedings of the XVI European Conference on Soil Mechanics and Geotechnical Engineering (2015)

4. R. Baum, T. Miyagi, S. Lee, O. Trofymchuk, Introduction: Hazard Mapping. Landslide Science for a Safer Geoenvironment (Springer, Cham, 2014)

5. O. Trofymchuk, Y. Kalyukh, H. Hlebchuk, Mathematical and GIS-modeling of landslides in Kharkiv region of Ukraine. Landslide Science and Practice: Spatial Analysis and Modelling (Springer, Berlin, 2013)

6. O.T. Azimov, I.V. Kuraeva, O.M. Trofymchuk, S.P. Karmazynenko, Ye.M. Dorofey, YuYu. Voytyuk, Estimation of the heavy metal pollution for the soils and different environmental objects within the solid domestic waste landfills. Conference Proceedings, 18th International Conference on Geoinformatics Theoretical and Applied Aspects (2019)

7. A.M. Gomilko, N.S. Gorodetskaya, A.N. Trofimchuk, Harmonic vibrations of a rigid impervious punch on a porous elastic base. International Applied Mechanics 35 (1999)

8. O. Trofymchuk, I. Kaliukh, K. Silchenko, V. Polevetskiy, V. Berchun, T. Kalyukh, Use accelerogram of real earthquakes in the evaluation of the stress-strain state of landslide slopes in seismically active regions of Ukraine. Engineering Geology for Society and Territory - Volume 2 (Springer, Cham, 2015)

9. O. Trofymchuk, Yu. Kalyukh, I. Trofimova, H. Hlebchuk, Modelling of Landslide Hazards in Kharkov Region of Ukraine Using GIS. Landslides: Global Risk Preparedness (Springer, Berlin, Heidelberg, 2013)

10. A.M. Gomilko, A.N. Trofimchuk, Asymptotic Solution of Contact Harmonic Problem for an Impenetrable Stamp on a Poroelastic Base. International Journal of Fluid Mechanics Research, 28, 1-2 (2001)

11. A.N. Trofimchuk, Unsteady Oscillations of a Liquid-Saturated Poroelastic Soil Layer. International Journal of Fluid Mechanics Research, 29, 1 (2002)

12. I. Kaliukh, O. Trofymchuk, G. Farenyuk, O. Ivanik, S. Shekhunova, Practical measures fo landslide risk mitigation in the Ukrainian Carpathians. First EAGE Workshop on Assessment of Landslide and Debris Flows Hazards in the Carpathians (2019) 
13. O. Trofymchuk, O. Kolodyazhnyy, E. Yakovlev, Hazardous activation of landslides within Western Carpathian Region (Ukraine). Landslide Science for a Safer Geoenvironment (Springer, Cham, 2014)

14. O.M. Trofymchuk, V.M. Trysnyuk, V.O. Okhariev, Environmental security management of geosystems. 18th International Conference on Geoinformatics - Theoretical and Applied Aspects, Extended Abstracts (2019)

15. A.N. Trofimchuk, V.A. Vasyanin, Simulation of packing, distribution and routing of small-size discrete flows in a multicommodity network. Journal of Automation and Information Sciences, 47, 7 (2015)

16. M. Myrontsov, O. Karpenko, O. Trofymchuk, V. Okhariev, Y. Anpilova, Increasing vertical resolution in electrometry of oil and gas wells. Systems, decision and control in energy II. Studies in systems, decision and control. (Springer, Cham, 2021), (to be published)

17. O. Trofymchuk, Y. Yakovliev, Y. Anpilova, M. Myrontsov, V. Okhariev, Ecological situation of post-mining regions in Ukraine. Systems, decision and control in energy II. Studies in systems, decision and control. (Springer, Cham, 2021), (to be published)

18. O. Trofymchuk, M. Myrontsov, V. Okhariev, Y. Anpilova, V. Trysnyuk, Transdisciplinary analytical system for support the environmental researches. Systems, decision and control in energy II. Studies in systems, decision and control (Springer, Cham, 2021), (to be published)

19. M.L. Myrontsov, O.M. Karpenko, O.M. Trofymchuk, V.O. Okhariev, Examples of determination of spatial and geoelectric parameters of productive beds of deposits of the Dnipro-Donetsk depth. XIV International Scientific Conference "Monitoring of Geological Processes and Ecological Condition of the Environment", Extended Abstracts (2020)

20. Trysnyuk, V.M , Okhariev, V.O., Trysnyuk, T.V., Zorina, O.V., Kurylo, A.V., Golovan, Y.V., Smetanin, K.V., Radlowska, K.O. Improving the algorithm of satellite images landscape interpretation. 18th International Conference Geoinformatics - Theoretical and Applied Aspects, Extended Abstracts. 2019.

21. O. Korchenko, V. Pohrebennyk, D. Kreta, V. Klymenko, Y. Anpilova, GIS and remote sensing as important tools for assessment of environmental pollution. 19th International Multidisciplinary Scientific GeoConference SGEM 2019, Extended Abstracts, 19, 2.1 (2019)

22. O. Trofymchuk, Y. Anpilova, Y. Yakovliev, I. Zinkiv, Ground Deformation Mapping of Solotvyno Mine Area Using Radar Data and GIS. 19th International Conference Geoinformatics:
Theoretical and Applied Aspects, Extended Abstracts (2020)

23. Y. Anpilova, Y. Yakovliev, I. Drozdovych, Landscape and Geological Factors of Water and Ecological Conditions Technogenesis of Donbas at the Post-Mining Stage. 19th International Conference Geoinformatics: Theoretical and Applied Aspects, Extended Abstracts (2020)

24. V. Lukianova, O. Trofymchuk, Y. Anpilova, Environmental safety of motor transport enterprises within the urban areas. Journal of Ecological Engineering, 21, 4 (2020)

25. O. Trofymchuk, V. Klymenko, Y. Anpilova, N. Sheviakina, S. Zagorodnia, The aspects of using GIS in monitoring of environmental components 20th International Multidisciplinary Scientific GeoConference SGEM (2020)

26. O. Karpenko, M. Myrontsov, I. Karpenko, V. Sobol, Detection conditions of gas-saturated layers by the result of complex interpretation of non-electrical well logging data. XIV International Scientific Conference "Monitoring of Geological Processes and Ecological Condition of the Environment", Extended Abstracts (2020)

27. M.L. Myrontsov, Electrometry effective inverse problem solving method. 19th International Conference Geoinformatics - Theoretical and Applied Aspects, Extended Abstracts (2020)

28. M.L. Myrontsov, Lateral logging sounding and lateral logging complex effective inverse problem solving method. 19th International Conference Geoinformatics - Theoretical and Applied Aspects, Extended Abstracts (2020)

29. M.L. Myrontsov, Multi-Probe Hardware for Electrometry of Oil and Gas Wells. Science and innovation, 14, 3 (2018)

30. M.L. Myrontsov, Lateral logging sounding and lateral logging complex effective inverse problem solving method. 19th International Conference Geoinformatics - Theoretical and Applied Aspects, Extended Abstracts (2020)

31. M.L. Myrontsov, A new method and program for multiprobe electric logging quantitative interpretation. Geoinformatics 2012 - 11th International Conference on Geoinformatics: Theoretical and Applied Aspects, Extended Abstracts (2012)

32. M.L. Myrontsov, The method to research equivalent solutions zones for inverse problem of well logging electrometry. XIII International Scientific Conference "Monitoring of Geological Processes and Ecological Condition of the Environment", Extended Abstracts (2019)

33. M.L. Myrontsov, The method to solve the inverse problem of lateral logging sounding and lateral logging. XIII International Scientific Conference "Monitoring of Geological Processes and Ecological Condition of the Environment", Extended Abstracts (2019) 
34. .Trysnyuk, V., Demydenko, O., Smetanin, K. and Zozulia, A. (2020), "Improvement of the complex evaluation method of vital activity risks", European Association of Geoscientists \& Engineers, Geoinformatics: Theoretical and Applied Aspects 2020,

35. Lupenko S., Lutsyk N., Yasniy O., Zozulia A. The Modeling and Diagnostic Features in the Computer Systems of the Heart Rhythm Analysis with the Increased Informativeness. 2019 9th International Conference on Advanced Computer Information Technologies (ACIT). IEEE, 2019. pp. 121-124.

36. King E. G. Identfying Linkages Amond Conceptual Models of Ecosystem Degradation and Restoration : Towards an integrative Framework / E. G. King and R. J. Hobbs // Restoration Ecology, 2006. - Volume 14, Issue 3. - PP. 369-378.

37. Whisenant S.G. Repairing Damaged Wildlands / S. G. Whisenant. - Cambridge : Cambridge University Press, 1999.-PP. 14-39.

38. Kainz, W.(2005): Fuzzy Logic and GIS, Department of Geography and Regional Research, University of Vienna, Austria, 2005.

39. Vitec M.A. Hrubes J., Kozumplik J. Waveletbased ECG delineation in Multilead ECG signals: Evaluation on the CSE Database. IFMBE Proceedings. 2009. Vol.25. P. 177-180.

40. Lupenko, N. Lutsyk, O. Yasniy and Ł. Sobaszek, "Statistical analysis of human heart with increased informativeness," Acta mechanica et automatica, vol. 12, 2018, pp. 311-315.

41. G. S. Brandão et al., "Analysis of heart rate variability in the measurement of the activity of the autonomic nervous system: technical note,". Manual Therapy, Posturology \& Rehabilitation Journal, 12, pp. 243-251, 2014.

42. Sassi R., Cerutti S., Lombardi F., and etc. "Advances in heart rate variability signal analysis: joint position statement by the eCardiology ESC Working Group and the European Heart Rhythm Association coendorsed by the Asia Pacific Heart Rhythm Society" EP Europace, vol. 17, 2015, pp 13411353.

43. Khaled Daqrouq QRS Complex Detection Based on Symmlets Wavelet Function / Khaled Daqrouq, Ibrahim N. AbuIsbeih, Abdel-Rahman Al-Qawasmi. 5th International MultiConference on Systems, Signals and Devices. 2008.

44. Chen S.-W. A real-time QRS detection method based on moving-averaging incorporating with wavelet denoising / S.-W. Chen, H.-C. Chen, H.L. Chan // Computer Methods and Programs in Biomedicine. - Elsevier Inc., 2006. - Vol. 82, pp. 187-195.

45. Sandeep Raj, Kailash Chandra Ray. Sparse representation of ECG signals for automated recognition of cardiac arrhythmias, Expert Systems with Applications, Vol. 105, 2018. P. 49-64.

46. Singh N., Kegan J.,M., Wilcox J., C., Hadley D., Plews D., and Froelocher V. "Heart Rate Variability: An Old Metric with New Meaning in the Era of using mHealth Technologies for Health and Exercise Training Guidance. Part One: Physiology and Methods" Arrhythmia \& electrophysiology Review, vol. 7, 2018, pp 193-198.

47. Azimov O.T., Shevchuk O.V. Geoinformation systems in monitoring studies of environmental pollution factors in the areas of municipal solid waste landfills. Earthdoc [Електронний ресурс]. EAGE. Vol. 2020.

48. Trysnyuk V. Comprehensive environmental monitoring based on aerospace and ground research data / *V. Trysnyuk, V. Prystupa, T. Trysnyuk, V. Vasylenko, A. Kurylo // Geoinformatics 2020 11-14 May 2020, Kyiv, Ukraine p.1-4.

49. Krasovska I. Complex space monitoring data analysis to determine environmental trends of poland-ukraine border areas / I. Krasovska, O. Butenko, S. Horelik, Y. Zakharchuk // Architecture civil engineering environment. - Vol. 13. 2020. - № 2. - p. 39-56. 